\title{
An Undoped, Single-Phase Oxide Photocatalyst Working under Visible Light
}

\author{
Hyun Gyu Kim, Dong Won Hwang, and Jae Sung Lee* \\ Department of Chemical Engineering and School of Environmental Science \& Engineering, \\ Pohang University of Science and Technology, San 31 Hyoja-dong, Pohang 790-784, Republic of Korea
}

Received January 19, 2004; E-mail: jlee@postech.ac.kr

Photocatalysts convert solar energy into clean hydrogen energy by splitting water, and decompose harmful organic and inorganic pollutants. The remarkable progress of the past decade in photocatalysis has been limited to ultraviolet (UV) light instead of the more useful visible-light region. The development of visible-light photocatalysts, therefore, has become one of the most important topics in photocatalysis research today. Traditional visible-light photocatalysts are either unstable ${ }^{1}$ (CdS, CdSe, etc.) or have low activity ${ }^{2}\left(\mathrm{Fe}_{2} \mathrm{O}_{3}, \mathrm{WO}_{3}\right.$, etc). Recently, some UV-active oxides turned into visible-light photocatalysts by substitutional doping of metals as in $\mathrm{Ni}_{x} \mathrm{In}_{1-x} \mathrm{TaO}_{4}{ }^{3}$ and (V-, $\mathrm{Fe}$-, or $\mathrm{Mn}$-) TiO ${ }_{2},{ }^{4}$ or of $\mathrm{C}, \mathrm{N}$, and $\mathrm{S}$, as in $\mathrm{TiO}_{2-x} \mathrm{~N}_{x},{ }^{5} \mathrm{TiO}_{2-x} \mathrm{C}_{x},{ }^{6} \mathrm{TaON},{ }^{7}$ and $\mathrm{Sm}_{2} \mathrm{Ti}_{2} \mathrm{O}_{5} \mathrm{~S}_{2}{ }^{8}$ But their activities are usually low, and there is concern for the stability of substituted anions under reaction conditions. Here we describe an undoped, single-phase oxide photocatalyst, $\mathrm{PbBi}_{2} \mathrm{Nb}_{2} \mathrm{O}_{9}$, an Aurivillius-phase perovskite, which is an efficient photocatalyst for isopropyl alcohol degradation to $\mathrm{CO}_{2}$, generation of photocurrent, and decomposition of water into $\mathrm{O}_{2}$ or $\mathrm{H}_{2}$, all under visible light $(\lambda \geq 420 \mathrm{~nm})$. It is much more active than the recently disclosed $\mathrm{TiO}_{2-x} \mathrm{~N}_{x}^{5}$ and, in particular, exhibits an unusually high quantum yield (QY, the number of photons utilized for a desired chemical reaction divided by the number of photons absorbed by the catalyst) of $29 \%$ in oxygen production from water containing $\mathrm{AgNO}_{3}$. Further, the material was found to be stable in water under irradiation conditions.

Perovskite-type oxide materials based on transition metals with $\mathrm{d}(0)$ electron configuration such as $\mathrm{Nb}(\mathrm{V}),{ }^{9} \mathrm{Ta}(\mathrm{V}),{ }^{10}$ and $\mathrm{Ti}(\mathrm{IV})^{11}$ are efficient photocatalysts for overall water splitting with high quantum yields. However, the large band gaps of these materials (ca. 3.8-4 eV) are not suitable for visible light-induced photocatalysis. Although $\mathrm{PbBi}_{2} \mathrm{Nb}_{2} \mathrm{O}_{9}$ also belongs to the layered perovskites, it absorbs visible light $(\lambda \geq 420 \mathrm{~nm})$ and shows high photocatalytic activities. Aurivillius compounds with a general formula $\left(\mathrm{Bi}_{2} \mathrm{O}_{2}\right)^{2+}\left(\mathrm{A}_{m-1} \mathrm{~B}_{m} \mathrm{O}_{3 m+1}\right)^{2-}$ consist of $m$ perovskite units sandwiched between bismuth oxide layers, where $\mathrm{A}$ and $\mathrm{B}$ are the two types of cations that enter the perovskite unit. ${ }^{12}$ The material was synthesized by the solid-state reactions of $\mathrm{PbO}, \mathrm{Bi}_{2} \mathrm{O}_{3}, \mathrm{Nb}_{2} \mathrm{O}_{5}$ at $1473 \mathrm{~K}$ (see Supporting Information.) The crystal structure of prepared material was confirmed from the X-ray diffraction (XRD) analysis using $\mathrm{Cu} \mathrm{K} \alpha$ radiation. As shown in Figure 1, highly crystalline $\mathrm{PbBi}_{2} \mathrm{Nb}_{2} \mathrm{O}_{9}$ was identified with a space group of $A_{21} \mathrm{am}$, $a=b=5.496 \AA$, $\mathrm{c}=25.55 \AA$. Its structure model is also shown together with the high-resolution TEM image that clearly exhibits fringes corresponding to repeating perovskite slabs. $\mathrm{TiO}_{2-x} \mathrm{~N}_{x}$, known for its good photocatalytic activity in decomposition of methylene blue and acetaldehyde under visible light was also prepared as a reference. ${ }^{5}$

The UV-visible diffuse reflectance spectra for these compounds are shown in Figure 2. From these spectra, we estimated the band gap energy of these materials as summarized in Table 1. The $\mathrm{PbBi}_{2} \mathrm{Nb}_{2} \mathrm{O}_{9}$ sample showed a sharp edge, while $\mathrm{TiO}_{2-x} \mathrm{~N}_{x}$

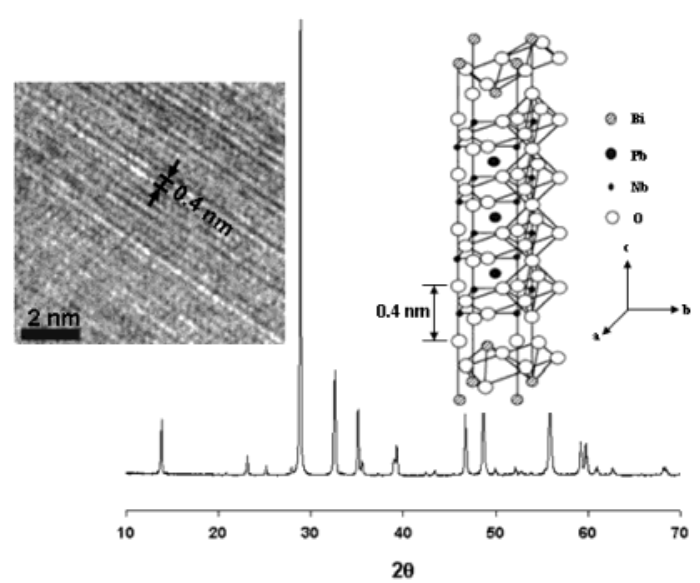

Figure 1. X-ray diffraction pattern and the high-resolution TEM image of $\mathrm{PbBi}_{2} \mathrm{Nb}_{2} \mathrm{O}_{9}$ sintered at $1473 \mathrm{~K}$ for $24 \mathrm{~h}$ and its structure model.

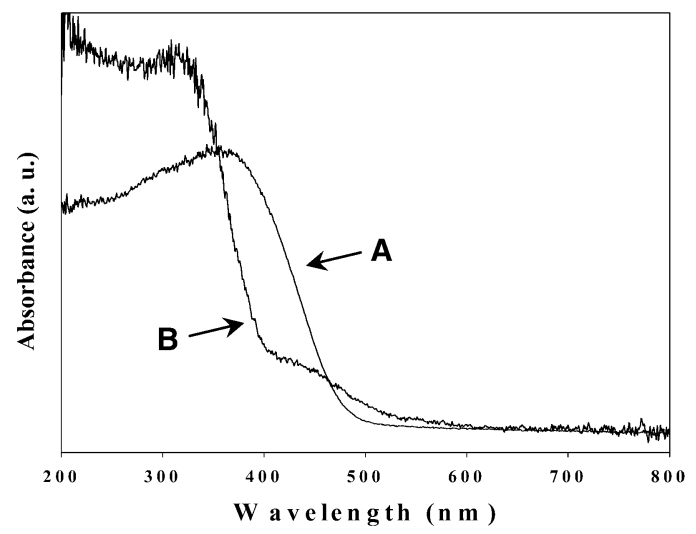

Figure 2. $\mathrm{UV}-$ vis diffuse reflectance of (A) $\mathrm{PbBi}_{2} \mathrm{Nb}_{2} \mathrm{O}_{9}$ and $(\mathrm{B}) \mathrm{TiO}_{2-x} \mathrm{~N}_{x}$.

Table 1. Photocatalytic Activities for $\mathrm{H}_{2}$ Evolution from an Aqueous Methanol Solution and $\mathrm{O}_{2}$ Evolution from Aqueous $\mathrm{AgNO}_{3}{ }^{a}$

\begin{tabular}{|c|c|c|c|c|c|c|}
\hline \multirow[b]{2}{*}{ catalyst } & \multicolumn{2}{|c|}{ band gap energy } & \multicolumn{2}{|c|}{$\mathrm{H}_{2}$ evolution } & \multicolumn{2}{|c|}{$\mathrm{O}_{2}$ evolution } \\
\hline & $E_{g}(\mathrm{eV})$ & $\lambda(\mathrm{nm})^{b}$ & $\mu \mathrm{mol} / \mathrm{h}$ & $Q Y^{c}$ & $\mu \mathrm{mol} / \mathrm{h}$ & $Q Y^{c}$ \\
\hline $\mathrm{PbBi} 2 \mathrm{Nb} 2 \mathrm{O} 9$ & 2.88 & 431 & 7.6 & 0.95 & 520 & 29 \\
\hline $\mathrm{TiO} 2-\mathrm{xNx}$ & 2.73 & 451 & Trace & 0 & 221 & 14 \\
\hline
\end{tabular}

${ }^{a}$ Catalyst loaded with $1 \mathrm{wt} \% \mathrm{Pt}, 1.0 \mathrm{~g}$; light source, 450-W W-Arc lamp (Oriel) with UV cutoff filter $(\lambda \geq 420 \mathrm{~nm})$. Reaction was performed in aqueous methanol solution (methanol $30 \mathrm{~mL}+$ distilled water $170 \mathrm{~mL}$ ) or in an aqueous $\mathrm{AgNO}_{3}$ solution $(0.05 \mathrm{~mol} / \mathrm{l}, 200 \mathrm{~mL}){ }^{b}$ The wavelength at the absorption edge, $\lambda$, was determined as the intercept on the wavelength axis for a tangent line drawn on absorption spectra. ${ }^{c}$ The quantum yield $\mathrm{QY}=2 \times$ number of $\mathrm{H}_{2}$ or $4 \times$ number of $\mathrm{O}_{2}$ generated per number of photon absorbed by photocatalyst. See Supporting Information.

showed two absorption edges; the main edge due to the oxide at $390 \mathrm{~nm}$ and a shoulder due to the nitride at $451 \mathrm{~nm}$. The color of both materials was yellow, indicating that these materials indeed 


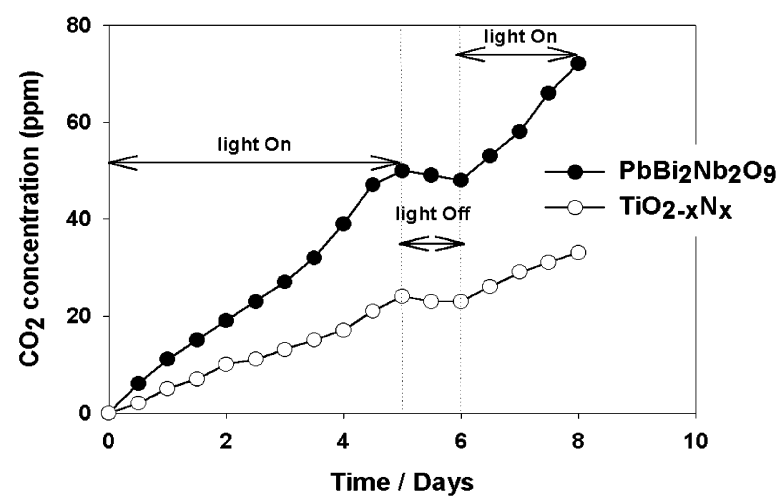

Figure 3. Time courses of $\mathrm{CO}_{2}$ evolution from IPA decomposition over $\mathrm{PbBi}_{2} \mathrm{Nb}_{2} \mathrm{O}_{9}$ and $\mathrm{TiO}_{2-} \mathrm{N}_{x}$ under visible light irradiation $(\lambda \geq 420 \mathrm{~nm})$. Photocatalyst, $0.3 \mathrm{~g}$; IPA concentration, $200 \mathrm{ppm}$ in air.

absorbed the visible light. These band gap energies are also greater than theoretical energy required for water splitting $(>1.23 \mathrm{eV})$.

To evaluate the photocatalytic activities of these materials under visible light ( $\lambda \geq 420 \mathrm{~nm}$ ), oxidative decomposition of gaseous isopropyl alcohol (IPA) was tested first. Figure 3 shows gaseous $\mathrm{CO}_{2}$ concentrations, generated as a result of the photodegradation of IPA over $\mathrm{PbBi}_{2} \mathrm{Nb}_{2} \mathrm{O}_{9}$ and $\mathrm{TiO}_{2-x} \mathrm{~N}_{x}$, as a function of irradiation time. The concentration of $\mathrm{CO}_{2}$ increased steadily with irradiation time at a decomposition rate of ca. $9.3 \times 10^{-3} \mathrm{~mol} / \mathrm{h}$ only under irradiation of light. The $\mathrm{CO}_{2}$ production stopped when light was turned off and was resumed at the same rate when light was turned on again. The photocatalytic activity of $\mathrm{TiO}_{2-x} \mathrm{~N}_{x}$ for IPA decomposition was about a half of that for $\mathrm{PbBi}_{2} \mathrm{Nb}_{2} \mathrm{O}_{9}$.

Active photocatalysts should generate photocurrents upon absorption of light, ${ }^{13}$ and we found that $\mathrm{PbBi}_{2} \mathrm{Nb}_{2} \mathrm{O}_{9}$ indeed generated photocurrent under visible light irradiation (see Supporting Information). Undoped $\mathrm{TiO}_{2}$ did not generate any current, while $\mathrm{TiO}_{2-x} \mathrm{~N}_{x}$ generated about half the current measured for $\mathrm{PbBi}_{2} \mathrm{Nb}_{2} \mathrm{O}_{9}$.

Finally, photocatalytic reduction of $\mathrm{H}_{2} \mathrm{O}$ into $\mathrm{H}_{2}$ and oxidation of $\mathrm{H}_{2} \mathrm{O}$ into $\mathrm{O}_{2}$ were performed as test reactions. Methanol and silver ions were used as scavengers of holes and photoelectrons, respectively. In Table $1, \mathrm{H}_{2}$ evolution from aqueous methanol solutions and $\mathrm{O}_{2}$ evolution from aqueous $\mathrm{AgNO}_{3}$ solution over these photocatalysts are summarized. $\mathrm{H}_{2}$ evolution was observed only over $\mathrm{PbBi}_{2} \mathrm{Nb}_{2} \mathrm{O}_{9}$ when $\mathrm{Pt}$ was loaded on its surface. $\mathrm{H}_{2}$ was evolved steadily with no indication of catalyst deactivation during $20 \mathrm{~h}$, and no reaction took place without irradiation. The estimated quantum yield of $\mathrm{Pt} / \mathrm{PbBi}_{2} \mathrm{Nb}_{2} \mathrm{O}_{9}$ for $\mathrm{H}_{2}$ evolution was ca. $0.95 \%$. The quantum yield for $\mathrm{O}_{2}$ evolution on $\mathrm{PbBi}_{2} \mathrm{Nb}_{2} \mathrm{O}_{9}$ was estimated to be ca. $29 \%$. $\mathrm{TiO}_{2-} \mathrm{N}_{x}$ showed a trace amount of $\mathrm{H}_{2}$ evolution, but the quantum yield for $\mathrm{O}_{2}$ evolution was as high as ca. $12 \%$. The quantum yield of $\mathrm{PbBi}_{2} \mathrm{Nb}_{2} \mathrm{O}_{9}$ for both $\mathrm{H}_{2}$ and $\mathrm{O}_{2}$ evolution, to our best knowledge, is one of the highest reported for semiconductor photocatalysts under visible light, and the high quantum yield for $\mathrm{O}_{2}$ formation is particularly impressive. Only TaON showed comparable quantum yields with ca. $0.2 \%$ for $\mathrm{H}_{2}$ production and ca. $34 \%$ for $\mathrm{O}_{2}$ production under similar conditions. ${ }^{7}$

$\mathrm{PbBi}_{2} \mathrm{Nb}_{2} \mathrm{O}_{9}$, a novel photocatalyst, has been discovered that shows high photocatalytic activities for degradation of organic pollutants, generation of photocurrent, and decomposition of water to form either $\mathrm{O}_{2}$ or $\mathrm{H}_{2}$, all under visible right irradiation $(\lambda \geq 420$ $\mathrm{nm})$. According to the band structure calculation using the Wien 97 program $^{14}$ (see Supporting Information), the conduction and valence bands of this compound consist mostly of empty Nb4d and occupied $\mathrm{O} 2 \mathrm{p}$ orbitals, respectively, but the latter is hybridized with Bi6s and Pb6s. This hybridization would push up the position of the valence band, giving the smaller band gap compared to compounds that do not contain $\mathrm{Pb}$ and $\mathrm{Bi}$ in their structures. ${ }^{15}$ It is notable that this reduction in the band gap energy of $\mathrm{PbBi}_{2} \mathrm{Nb}_{2} \mathrm{O}_{9}$ is accomplished without any dopant such as nitrogen as in $\mathrm{TiO}_{2-x} \mathrm{~N}_{x}$. Although dopants such as $\mathrm{N}, \mathrm{Fe}$, and $\mathrm{Cr}$ could induce the visible light absorption, they also serve as sites for electron-hole recombination that leads to low quantum yields. In any case, this work is the first example of an undoped, single-phase oxide photocatalyst that shows such high reactivities. Its activities are much higher than those for most of the previously reported materials, especially in oxygen generation from water containing $\mathrm{AgNO}_{3}(\mathrm{QY}=29 \%)$. In this regard, it is an important discovery that the visible light could be absorbed and induce both photocatalytic reduction and oxidation without any dopant for $\mathrm{PbBi}_{2} \mathrm{Nb}_{2} \mathrm{O}_{9}$. Since it is a single-phase oxide, there is much less concern for stability under light irradiation. Indeed, its crystal structure did not change and postreaction analysis of the reaction solution showed no indication of dissolved catalyst components even after more than $100 \mathrm{~h}$ of water decomposition reaction under visible light (see Supporting Information).

Acknowledgment. This work has been supported by Hydrogen Energy R\&D Center, the Research Center for Energy Conversion and Storage, and National R\&D Project for Nano Science and Technology of the Korea Ministry of Science and Technology, and BK 21 Program.

Supporting Information Available: Experimental procedures, photocurrent generation, calculated total and partial density of states of $\mathrm{PbBi}_{2} \mathrm{Nb}_{2} \mathrm{O}_{9}, \mathrm{XRD}$ patterns before and after water decomposition over $\mathrm{PbBi}_{2} \mathrm{Nb}_{2} \mathrm{O}_{9}$. X-ray crystallographic file for $\mathrm{PbBi}_{2} \mathrm{Nb}_{2} \mathrm{O}_{9}$ in CIF format. These materials are available free of charge via the Internet http://pubs.acs.org.

\section{References}

(1) De, G. C.; Roy, A. M.; Bhattacharya, S. S. Int. J. Hydrogen Energy 1996 , $21,19$.

(2) Hwang, D. W.; Kim, J.; Park, T. J.; Lee, J. S. Catal. Lett. 2002, 80, 53.

(3) Zou, Z.; Ye, J.; Sayama, K.; Arakawa, H. Nature 2001, 424, 625.

(4) Yamashita, H.; Harada, H.; Misaka, J.; Takeuchi, M.; Ikeue, K.; Anpo, M. J. Photochem. Photobiol. A 2002, 148, 257.

(5) Asahi, R.; Morikawa, T.; Ohwaki, T.; Aoki, K.; Tao, Y. Science 2001, 293, 269.

(6) (a) Khan, S. U. M.; Al-Shahry, M.; Ingler, W. B., Jr. Science 2002, 297 , 2243; (b) Sakthivel, S.; Kisch, H. Angew. Chem., Int. Ed. 2003, 42, 4908.

(7) Hitoki, G.; Takata, T.; Kondo, J.; Hara, M.; Kobayashi, H.; Domen, K. Chem. Commun. 2002, 1698.

(8) Ishikawa, A.; Takata, T.; Kondo, J. N.; Hara, M.; Kobayashi, H.; Domen, K. J. Am. Chem. Soc. 2002, 124, 13547.

(9) Domen, K.; Kudo, A.; Shinozaki, A.; Tanaka, A.; Maruya, K.; Onishi, T. Chem. Commun. 1986, 356.

(10) Kim, H. G.; Hwang, D. W.; Kim, J.; Kim, Y. G.; Lee, J. S. Chem Cоттип. 1999, 1077.

(11) Kato, H.; Kudo, A. J. Phys. Chem. B 2001, 105, 4285.

(12) Du, X.; Chen, I.-W. J. Am. Ceram. Soc. 1998, 81, 3253.

(13) Park, H.; Choi, W. J. Phys. Chem. B 2003, 107, 3885.

(14) Blaha, P.; Schwarz, K.; Luitz, J. WIEN97; A Full Potential Linearized Augmented Plane Wave Package for Calculating Crystal Properties. Karlheinz Schwarz, Techn. Universität, Wien, Austria, 1999.

(15) Yoshimura, J.; Ebana, Y.; Kondo, J.; Domen, K.; Tanaka, A. J. Phys. Chem. B 1993, 97, 1970

JA049676A 